\title{
Dose-response evaluation of urinary cadmium and kidney injury biomarkers in Chinese residents and dietary limit standards
}

Ying Qing ${ }^{1}$, Jiaqi Yang ${ }^{1}$, Yuanshen Zhu' ${ }^{1}$ Yongzhen $\mathrm{Li}^{1}$, Weiwei Zheng ${ }^{2}$, Min Wu ${ }^{1}$ and Gengsheng He ${ }^{\text {* }}$

\begin{abstract}
Background: Cadmium (Cd) is a common heavy metal that mainly causes renal damage. There is a lack of research on the large-scale and systematic evaluation of the association between urinary $\mathrm{Cd}(\mathrm{U}-\mathrm{Cd})$ and various effect biomarkers among Chinese residents.

Methods: Based on the establishment process of dietary Cd limit standards by European Food Safety Authority (EFSA), the dose-response relationships between $\mathrm{U}$-Cd and four biomarkers, $\beta_{2}$-microglobulin ( $\beta_{2}-\mathrm{MG}$ ), $\mathrm{N}$-acetyl- $\beta$ glucosidase (NAG), microalbumin (mALB), and retinol binding Protein (RBP) were explored, respectively. Toxicokinetic model was used to derive the dietary $\mathrm{Cd}$ exposure limit for Chinese residents after critical $\mathrm{U}$-Cd concentration was calculated.
\end{abstract}

Results: As the sensitive biomarkers of renal injury, $\beta_{2}-M G$ and NAG were selected to estimate the $95 \%$ confidence interval lower limit of the U-Cd benchmark dose $\left(\mathrm{BMDL}_{5}\right)$ to be 3.07 and $2.98 \mu \mathrm{g} / \mathrm{g} \mathrm{Cr}$, respectively. Dietary Cd exposure limit was calculated to be $0.28 \mu \mathrm{g} / \mathrm{kg} \mathrm{bw} /$ day $(16.8 \mu \mathrm{g} / \mathrm{day}$, based on the body weight of $60 \mathrm{~kg})$, which was lower than the average Chinese $\mathrm{Cd}$ exposure $(30.6 \mathrm{\mu g} /$ day) by the China National Nutrient and Health Survey.

Conclusion: This study established an overall association between U-Cd and renal injury biomarkers, and explored the Chinese dietary $\mathrm{Cd}$ exposure limits, which helps improve Chinese $\mathrm{Cd}$ exposure risk assessment and provides a reference basis for formulating reasonable exposure standards.

Keywords: Cadmium, Toxicokinetic model, Effect biomarkers, Benchmark dose, Tolerable daily intake

\section{Introduction}

Cadmium $(\mathrm{Cd})$ is a toxic heavy metal commonly found in the environment, with an average concentration in the earth's crust of about $0.2 \mathrm{mg} / \mathrm{kg}$ [1]. With the development of social industry, human activities, such as mineral development, metal smelting, industrial emissions, fossil fuels, and waste incineration, have caused $\mathrm{Cd}$ to enter soil and water through farmland irrigation, atmospheric

\footnotetext{
*Correspondence: gshe@shmu.edu.cn

${ }^{1}$ School of Public Health/Key Laboratory of Public Health Safety,

Ministry of Education, Department of Nutrition and Food Science, Fudan University, No. 130 Dongan Road, Shanghai 200032, China

Full list of author information is available at the end of the article
}

dust reduction and urban compost [2,3] and lead to long-term and wide presence of $\mathrm{Cd}$ in the environment. Kidney is the main target organ of $\mathrm{Cd}$ exposure $[4,5]$. Adverse outcomes such as tubular injury, decreased glomerular reabsorption rate have been shown to be closely related to Cd exposure [6].

Considering the potential hazards of $\mathrm{Cd}$ exposure to human health, the European Food Safety Authority (EFSA) proposed a tolerable weakly intake (TWI) of $2.5 \mu \mathrm{g} / \mathrm{kg}$ bw/week for dietary Cd intake in 2009 [7]. The committee used a meta-analysis to determine the doseresponse relationship between urinary $\mathrm{Cd}(\mathrm{U}-\mathrm{Cd})$ and the renal injury biomarker $\beta_{2}$-microglobulin $\left(\beta_{2}-\mathrm{MG}\right)$. Benchmark dose lower-bound confidence limit (BMDL) original author(s) and the source, provide a link to the Creative Commons licence, and indicate if changes were made. The images or other third party material in this article are included in the article's Creative Commons licence, unless indicated otherwise in a credit line to the material. If material is not included in the article's Creative Commons licence and your intended use is not permitted by statutory regulation or exceeds the permitted use, you will need to obtain permission directly from the copyright holder. To view a copy of this licence, visit http://creativecommons.org/licenses/by/4.0/. The Creative Commons Public Domain Dedication waiver (http://creativeco mmons.org/publicdomain/zero/1.0/) applies to the data made available in this article, unless otherwise stated in a credit line to the data. 
of U-Cd, which was derived by Hill model, was used as the safety threshold dose. Based on the critical U-Cd concentration, corresponding external exposure limit was calculated by toxicokinetic (TK) model. The TK model is an in vitro mathematical model based on physiology, biochemistry, dissection and pharmacokinetics, which could simulate the internal exposure dose in specific organs based on the external exposure of pollutants, and provide reliable information for quantitative assessment of the metabolic concentrations of toxic chemicals [8]. At present, it has been widely used in the risk assessment of pollutants such as heavy metals, persistent organic pollutants, and organic pesticides [9-11].

By integrating and reanalyzing the published data, a comprehensive meta-analysis can reduce the uncertainty in a single study and improve the representativeness of the analysis results [12]. This is also a commonly used method for establishing pollutant limit standards and safety thresholds and risk assessments internationally [7, 10]. However, China has not established dietary Cd exposure limits based on the exposure characteristics of Chinese. In previous risk assessment studies, international standards such as EFSA or the Joint FAO/WHO Expert Committee on Food Additives (JECFA) standards were often used to evaluate the risk of the Chinese residents. The Cd pollution status and dietary patterns of the main data sources of the above standards, such as Europe and Japan, are quite different from those of China, inevitably affecting the accuracy of $\mathrm{Cd}$ exposure risk assessment in China. Therefore, it is essential to investigate the sensitive effect biomarker of $\mathrm{Cd}$ exposure and reference dietary $\mathrm{Cd}$ intake in Chinese population.

This study is based on the epidemiological studies of $\mathrm{U}-\mathrm{Cd}$ and renal injury in China, aiming to evaluate the effects of $\mathrm{Cd}$ exposure on renal biomarkers in Chinese. In particular, this study attempts to (1) establish a doseresponse relationship between $\mathrm{U}-\mathrm{Cd}$ and renal biomarkers; (2) calculate the critical threshold dose of U-Cd in Chinese population based on continuous data; (3) use the TK model to calculate the dietary $\mathrm{Cd}$ exposure limit applicable to the Chinese population. As far as we know, this is the first study to conduct a large-scale systematic analysis of U-Cd and multiple effect biomarkers and estimate the tolerable dietary intake (TDI) limit of $\mathrm{Cd}$ in China. The results will provide reliable information for the establishment of dietary $\mathrm{Cd}$ limits and improve the risk assessment of $\mathrm{Cd}$ exposure among Chinese.

\section{Materials and methods Data collection}

In this study, renal injury effects were used as the endpoints of $\mathrm{Cd}$ exposure. Systematic screening was performed in four common databases (Web of Science,
PubMed, China National Knowledge Infrastructure (CNKI) and WANFANG Database). The U-Cd with renal injury biomarkers in Chinese were used as the research object to establish a comprehensive database.

Based on previous researches, four renal injury biomarkers were selected: $\beta_{2}-\mathrm{MG}, \mathrm{N}$-acetyl- $\beta$-glucosidase (NAG), microalbumin (mALB), and retinol binding Protein (RBP). Taking the $\beta_{2}$-MG as an example, the following search formulas were used to search in the databases: PubMed: Cadmium AND $\beta_{2}$-Microglobulin AND (China OR Hongkong OR Taiwan); Web of science: TS $=(\mathrm{Cad}-$ mium AND $\beta_{2}$-Microglobulin) AND $\mathrm{TS}=($ China OR Hongkong OR Taiwan); CNKI Database: $\mathrm{SU}=\mathrm{Cadmium}$ AND $\mathrm{SU}=\beta_{2}$-Microglobulin; WANFANG Database: Subject: (Cadmium)* Subject: ( $\beta_{2}$-Microglobulin). (Published time: 1980.1-2021.3).

Literatures were included in a consolidated database by detailed screening based on the following criteria: 1 . The study measured U-Cd (in $\mu \mathrm{g} / \mathrm{g}$ creatinine or other units that could be converted) as biomarker of internal dose together with at least one biomarker of renal injury both as continuous variables; 2 . If the research data are used in more than one study, the study providing the most complete and detailed information was chosen (e.g., the study which provides the most dose sub-groups); 3 . In order to reduce the heterogeneities, the outliers and sample size below 15 were excluded.

\section{Data processing}

In order to harmonize and validate the database, some further checks and transformations were performed. Abnormal values or data from the same population were double-checked. The units of U-Cd were adjusted in consistent. U-Cd values reported in $\mathrm{nmol} / \mathrm{mmol} \mathrm{Cr}$ were transformed into $\mu \mathrm{g} / \mathrm{g} \mathrm{Cr}$ by applying the factor of 0.99375 (=Molar Mass (Cd)/ Molar Mass (creatinine)) [13]. In addition, geometric mean (GM) and geometric standard deviation (GSD) were used to record the included data. If the study only provided the arithmetic mean (AM) and arithmetic standard deviation (SD), the following data transformations were made $[14,15]$ :

$$
\begin{aligned}
& \left.G M=A M / \sqrt{\left(1+(S D / A M)^{2}\right.}\right) \\
& G S D=\exp \left[\sqrt{\log \left(1+(S D / A M)^{2}\right)}\right]
\end{aligned}
$$

If only the median and range ( $\min , \max$ ) were provided, GM and GSD were converted according to the following formula [16]:

$$
G M=\text { Median }
$$




$$
G S D=e^{\max \left(\log (G M / \min ), \log (\max / G M) /^{-1}(1-1 / 2 n)\right.}
$$

where $\Phi$ represents the cumulative density function of the standardized Gaussian distribution and $n$ represents the sample size.

\section{Calculation of U-Cd safety threshold}

After the databases compilation, the benchmark dose software (BMDS) was used to calculate the BMD and BMDL. The Hill model (based on the EFSA, as preferred) and exponential model (as complementary) were used to evaluate the dose-response relationship between the mean dose of each population subgroup to the mean response. Akaike's information criterion was performed for model selection, and the model with the lowest Akaike's information criterion value was preferred. Goodness of fit test was conducted with the criteria of $P>0.05$. The benchmark response factor (BMRF) is set at $5 \%$. The risk type of BMR is extra for Hill model, indicating that the response associated with the BMR is the background estimate plus the product of the BMRF times the difference between the background estimate and the model estimates of the maximum response. The BMR type for exponential model is standard deviation (Std. Dev.), indicating the response associated with the BMR is the background estimate plus the product of the BMRF times the standard deviation for the control group data [17]. Among 4 biomarker databases, the BMD and BMDL of U-Cd were calculated and compared, and the lowest dose was selected as the safety threshold.

The dose-effect relationship described by Hill model is an S-shape with 4 parameters. The model equation is given by:

$$
\text { Effect }(d)=\text { background }+ \text { amplitude } \times\left(d^{\eta} /\left(d^{\eta}+e d_{50}^{\eta}\right)\right)
$$

where $d$ stands for the dose (U-Cd), 'amplitude' corresponds to the difference between the 2 plateaux of the $\mathrm{S}$-shape, ed50 corresponds to the dose where $50 \%$ of the maximal effect is achieved, and eta $(\eta)$ corresponds to the shape parameter defining the steepness of the $S$ curve. The exponential model, as a complementary model, is also used to fit the dose-effect relationship when the hill model does not fit well.

\section{Derivation of dietary Cd expose TDI}

Based on the U-Cd safety threshold, the TK model was used to estimate the TDI limits of the dietary Cd exposure. The formula of the TK model is as follows [18]:

$$
C d_{\text {urine }}(\text { age })=\frac{f_{u} \times f_{k}}{\log (2)} \times d \times t_{1 / 2} \frac{\left[1-\exp \left(-\frac{\log (2) \times \text { age }}{\mathrm{t}_{1 / 2}}\right)\right]}{\left[1-\exp \left(-\frac{\log (2)}{\mathrm{t}_{1 / 2}}\right)\right]}
$$

where $C d_{\text {urine }}$ (age) represents the $\mathrm{U}-\mathrm{Cd}(\mu \mathrm{g} / \mathrm{g} \mathrm{Cr})$ at specific age; $d$ is daily dietary $C d$ exposure $(\mu \mathrm{g} / \mathrm{kg} /$ day); $t_{1 / 2}$ is the half-life of $\mathrm{Cd}$ in the renal; $f_{u}^{*} f_{k}$ represents the comprehensive constant related to absorption. Parameters of the model referred to EFSA which were as follows [7, 18]: the half-life was drawn from a lognormal distribution (Mean: 11.6, SD: 3.0) to consider the variability among populations; age was set to be 50 years old; the absorption rate $\left(f_{u}^{*} f_{k}\right)$ is fixed at 0.0063 . In addition, considering the differences between the studies, adjustment factor $\left(\mathrm{AF}^{(95)}=3.9\right)$ was introduced to account for the lack of individual data and avoid overestimation of the TDI limit [7]. A total of 100,000 Monte Carlo sampling iterations was conducted to estimate the relative frequency distribution of dietary $\mathrm{Cd}$ exposure in the Chinese corresponding to the U-Cd at threshold dose using @Risk. To ensure that $95 \%$ of the residents' $\mathrm{U}-\mathrm{Cd}$ are below the safety threshold, the dietary $\mathrm{Cd}$ exposure corresponding to $5^{\text {th }}$ percentiles of the population reaching this threshold was selected as the TDI limit.

\section{Statistical analysis}

The BMD/BMDL was calculated by BMDS (Version 2.7.0, Environmental Protection Agency, USA; https:// www.epa.gov/bmds/benchmark-dose-software-bmdsversion-27-materials). @Risk 7.6 (Palisade software, USA) was used to conduct Monte Carlo sampling. Origin 2018 (OriginLab, Northampton, Massachusetts, USA) was used for drawing. SPSS 16.0 (SPSS Inc., Chicago, IL, USA) was used to perform other statistical analysis. Spearman correlation was used to determine the association between U-Cd and renal effect biomarkers. Mann-Whitney U test was used to compare the U-Cd or biomarkers among different subgroups. $P<0.05$ was considered as statistically significant.

\section{Results}

\section{Included studies}

After searching from 4 databases, a total of 158 studies were included in this study. The process of inclusion and exclusion of the study is shown in Fig. 1. Of all the included studies, 332 matched pairs of U-Cd and $\beta_{2}-M G$ levels can be gathered from 85 studies, followed by NAG ( $\mathrm{N}=29$ with 143 data), mALB ( $=23$ with 87 data), and $\mathrm{RBP}(\mathrm{N}=21$ with 74 data). All included publications are listed in the supplementary material (Table S3-6). The composition of gender and occupational status in the database of different effect biomarkers is detailed in the supplementary material (Table S1). The gender composition of each dataset is uniform, and the sample size of the non-occupational is higher than that of the occupational population. 


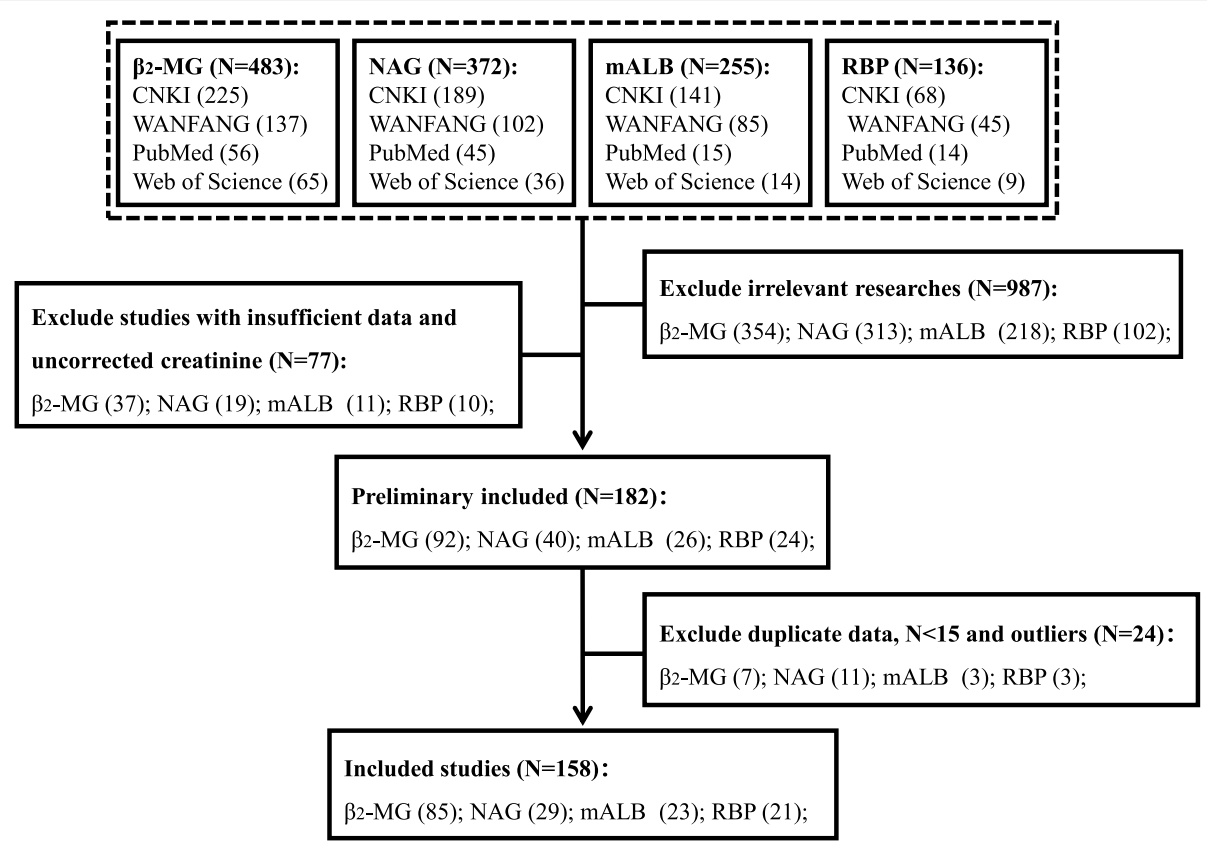

Fig. 1 Retrieval and exclusion flow chart of U-Cd and renal injury biomarkers

Table 1 Dataset characteristics and Spearman coefficients of $\mathrm{U}-\mathrm{Cd}$ and different effect biomarkers

\begin{tabular}{|c|c|c|c|c|}
\hline Dose-response & Mean (SD) & Median & $P_{10}-P_{90}$ & $\begin{array}{l}\text { Correlation } \\
\text { Coefficient }\end{array}$ \\
\hline \multicolumn{5}{|c|}{$\mathrm{U}-\mathrm{Cd} \& \beta_{2}-\mathrm{MG}(N=332)$} \\
\hline $\begin{array}{l}\mathrm{U}-\mathrm{Cd}(\mu \mathrm{g} / \mathrm{g} \\
\mathrm{Cr})\end{array}$ & $4.89(5.06)$ & 3.29 & $0.48-11.54$ & $0.569^{*}$ \\
\hline $\begin{array}{l}\beta_{2}-M G(\mu g / g \\
C r)\end{array}$ & $384.57(872.81)$ & 197.90 & $81.85-653.23$ & \\
\hline \multicolumn{5}{|c|}{ U-Cd \& NAG $(N=143)$} \\
\hline $\begin{array}{l}\mathrm{U}-\mathrm{Cd}(\mu \mathrm{g} / \mathrm{g} \\
\mathrm{Cr})\end{array}$ & $4.43(4.45)$ & 2.38 & $0.43-11.59$ & $0.398^{*}$ \\
\hline NAG (U/g Cr) & $8.18(5.56)$ & 7.64 & $2.21-14.02$ & \\
\hline \multicolumn{5}{|c|}{ U-Cd \& mALB $(N=87)$} \\
\hline $\begin{array}{l}\mathrm{U}-\mathrm{Cd}(\mu \mathrm{g} / \mathrm{g} \\
\mathrm{Cr})\end{array}$ & $4.23(3.95)$ & 2.49 & $0.77-10.41$ & 0.164 \\
\hline $\begin{array}{l}\mathrm{mALB}(\mathrm{mg} / \mathrm{g} \\
\mathrm{Cr})\end{array}$ & $7.66(6.67)$ & 5.10 & $2.79-15.78$ & \\
\hline \multicolumn{5}{|c|}{$\mathrm{U}-\mathrm{Cd} \& \mathrm{RBP}(N=74)$} \\
\hline $\begin{array}{l}\mathrm{U}-\mathrm{Cd}(\mu \mathrm{g} / \mathrm{g} \\
\mathrm{Cr})\end{array}$ & $6.12(4.96)$ & 4.56 & $0.87-12.60$ & 0.146 \\
\hline $\mathrm{RBP}(\mu \mathrm{g} / \mathrm{g} \mathrm{Cr})$ & $215.62(322.58)$ & 107.92 & $67.51-503.00$ & \\
\hline
\end{tabular}

\section{Characteristics of $\mathrm{U}-\mathrm{Cd}$ and four effect biomarkers}

The characteristics of U-Cd and four corresponding biomarkers $\left(\beta_{2}-\mathrm{MG}, \mathrm{NAG}, \mathrm{mALB}\right.$, and RBP) in each dataset are listed in Table 1 . In the database of $\beta_{2}-\mathrm{MG}$, the mean values of $\mathrm{U}-\mathrm{Cd}$ and $\beta_{2}-\mathrm{MG}$ are 4.89 and $384.6 \mu \mathrm{g} / \mathrm{g} \mathrm{Cr}$. In the NAG database, the mean values of U-Cd and NAG are $4.43 \mu \mathrm{g} / \mathrm{g} \mathrm{Cr}$ and $8.18 \mathrm{U} / \mathrm{g} \mathrm{Cr}$. In the $\mathrm{mALB}$ databases, the mean values of U-Cd and mALB are $4.23 \mu \mathrm{g} / \mathrm{g} \mathrm{Cr}$ and $7.66 \mathrm{mg} / \mathrm{g} \mathrm{Cr}$. In the database of RBP, the mean values of $\mathrm{U}-\mathrm{Cd}$ and RBP are 6.12 and $215.62 \mu \mathrm{g} / \mathrm{g} \mathrm{Cr}$, respectively. Spearman coefficients show that $\beta_{2}-\mathrm{MG}$ and NAG have significant positive correlations with U-Cd. The distribution characteristics of age, gender, and occupational exposure subgroups are listed in the supplementary material (Table S2). Figure 2 depicts the scatter plot of the U-Cd and four effect biomarkers on the log-log scale. Four biomarkers all show an increasing trend with U-Cd and the trend is more pronounced in high concentrations range.

\section{Urinary Cd safety threshold}

The dose-response relationship fit by Hill or exponential model of U-Cd and the four effect biomarkers are shown in Fig. 3. Except for mALB, which uses the exponential model for fitting, the other three effect biomarkers are all fitted by Hill model. For the four effect biomarkers of $\beta_{2}$ MG, NAG, mALB and RBP, the calculated $\mathrm{BMD}_{5}$ is 4.05 , $3.43,7.12$ and $7.22 \mu \mathrm{g} / \mathrm{g} \mathrm{Cr}$, respectively, and the $\mathrm{BMDL}_{5}$ is 3.07, 2.98, 4.17 and $5.46 \mu \mathrm{g} / \mathrm{g} \mathrm{Cr}$, respectively. The corresponding $\mathrm{U}-\mathrm{Cd}$ safety thresholds are listed in Table 2. The threshold dose of U-Cd derived by $\beta_{2}-\mathrm{MG}$ and NAG are lower than the results of the mALB and RBP. EFSA chose $\beta_{2}-\mathrm{MG}$ as the key biomarker, while NAG is the most sensitive biomarker in this study. Therefore, $\beta_{2}-\mathrm{MG}$ 

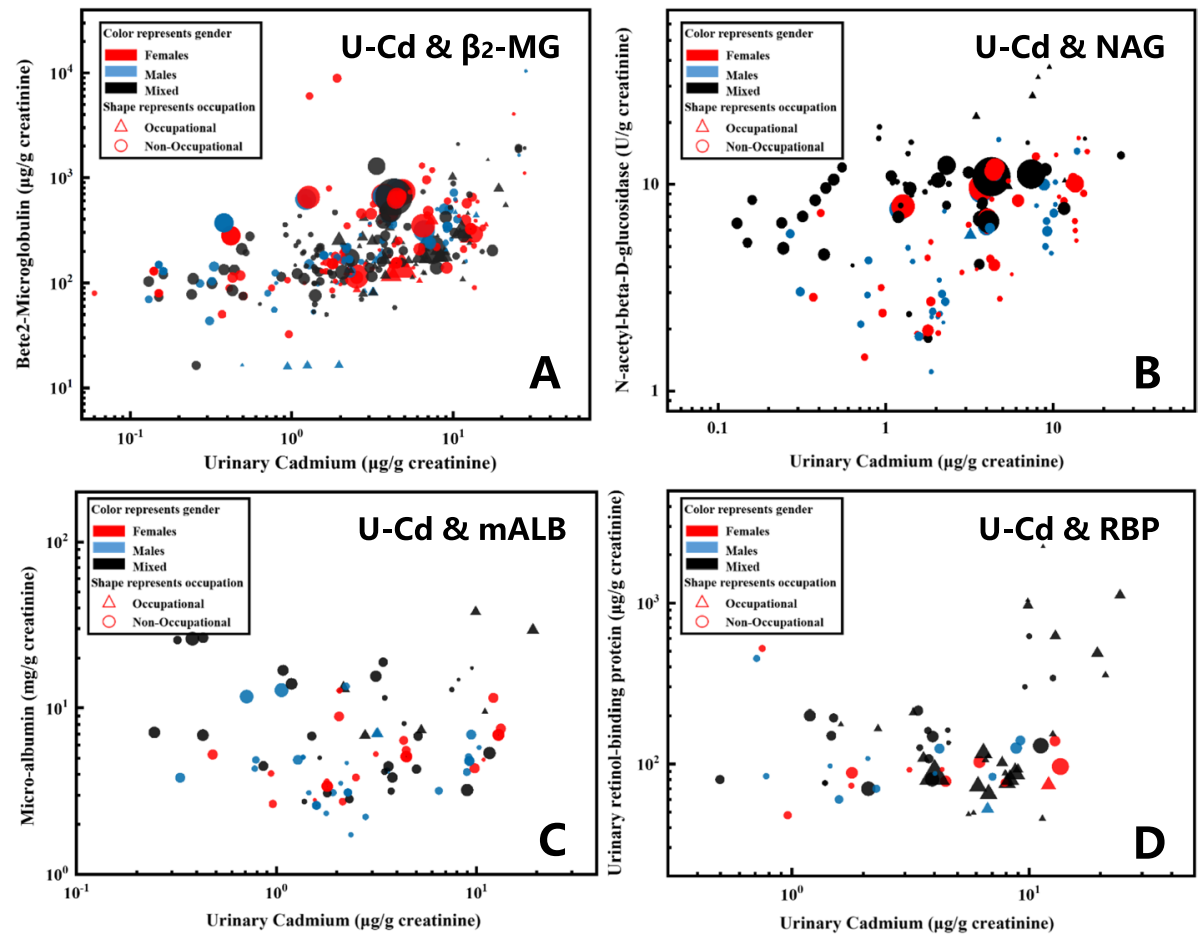

Fig. 2 The scatter plot for the U-Cd and renal effect biomarkers (Color represents gender: red (female); blue (male), black (gender information is not clear); shape represents occupational: round (non-occupational), triangle (occupational); dot size represents sample size: size $=$ sqrt (sample size)/158)

and NAG were both selected as sensitive biomarkers for comparison. The corresponding $\mathrm{BMDL}_{5}\left(\beta_{2}\right.$-MG: $3.07 \mu \mathrm{g} / \mathrm{g}$ Cr; NAG: $2.98 \mu \mathrm{g} / \mathrm{g} \mathrm{Cr}$ ) were used as U-Cd safety thresholds to derive the tolerable dietary $\mathrm{Cd}$ intake limits, respectively.

\section{Tolerable dietary intake for $\mathrm{Cd}$ exposure}

The cumulative probability distribution of dietary $\mathrm{Cd}$ exposure in Chinese population derived from the $\mathrm{BMDL}_{5}$ of U-Cd of NAG and $\beta_{2}$-MG is shown in Fig. 4. In order to protect most people from kidney injury caused by $\mathrm{Cd}$ exposure, the dietary intake corresponding to the 5\% quantile is selected as the TDI value, which are $0.28 \mu \mathrm{g} /$ $\mathrm{kg}$ bw/day for NAG and $0.29 \mu \mathrm{g} / \mathrm{kg}$ bw/day for $\beta_{2}$-MG, respectively. The more stringent value $(0.28 \mu \mathrm{g} / \mathrm{kg}$ bw $/$ day) was decided as the final TDI limit $(16.8 \mu \mathrm{g} /$ day, based on body weight of $60 \mathrm{~kg}$ ). Within this TDI, at least $95 \%$ of the population have U-Cd concentrations below the safe threshold.

\section{Discussion}

This study focused on the U-Cd and renal injury biomarkers among Chinese and conducted a comprehensive search for related studies. The dose-response relationships between U-Cd and four renal injury biomarkers were established using Hill or exponential model. $\beta_{2}$ MG and NAG were used as the sensitive biomarkers to determine the $\mathrm{BMDL}_{5}$ of $\mathrm{U}-\mathrm{Cd}$ safe thresholds $\left(\beta_{2}-\mathrm{MG}\right.$ : $3.07 \mu \mathrm{g} / \mathrm{g}$ Cr; NAG: $2.98 \mu \mathrm{g} / \mathrm{g}$ Cr). The TDI limit derived by TK model was determined to be $0.28 \mu \mathrm{g} / \mathrm{kg}$ bw/day. Within this limit, U-Cd concentrations of $95 \%$ of the residents in China would be below the safety threshold, effectively avoiding the risk of renal damage caused by dietary Cd exposure. This study provides reference for formulating of China's $\mathrm{Cd}$ exposure standards, which is conducive to objectively and accurately assessing the $\mathrm{Cd}$ exposure health risk of Chinese residents.

The dose-response relationship is the basis for risk assessment of pollutant exposure. In the past, the "No-observed-adverse-effect-level" (NOAEL), usually obtained by animal experiments, was commonly served as the potential key dose endpoint related to human health [19]. However, the dose setting, the sensitivity of the detection method and the sample size in the experimental design will have a great impact on the NOAEL results in practice. The BMD method, which was first proposed by Crump in 1984 [20], has been widely adopted in health risk assessment. The BMD is defined as the exposure level corresponding to a predetermined increase in the probability of an adverse response (e.g., 

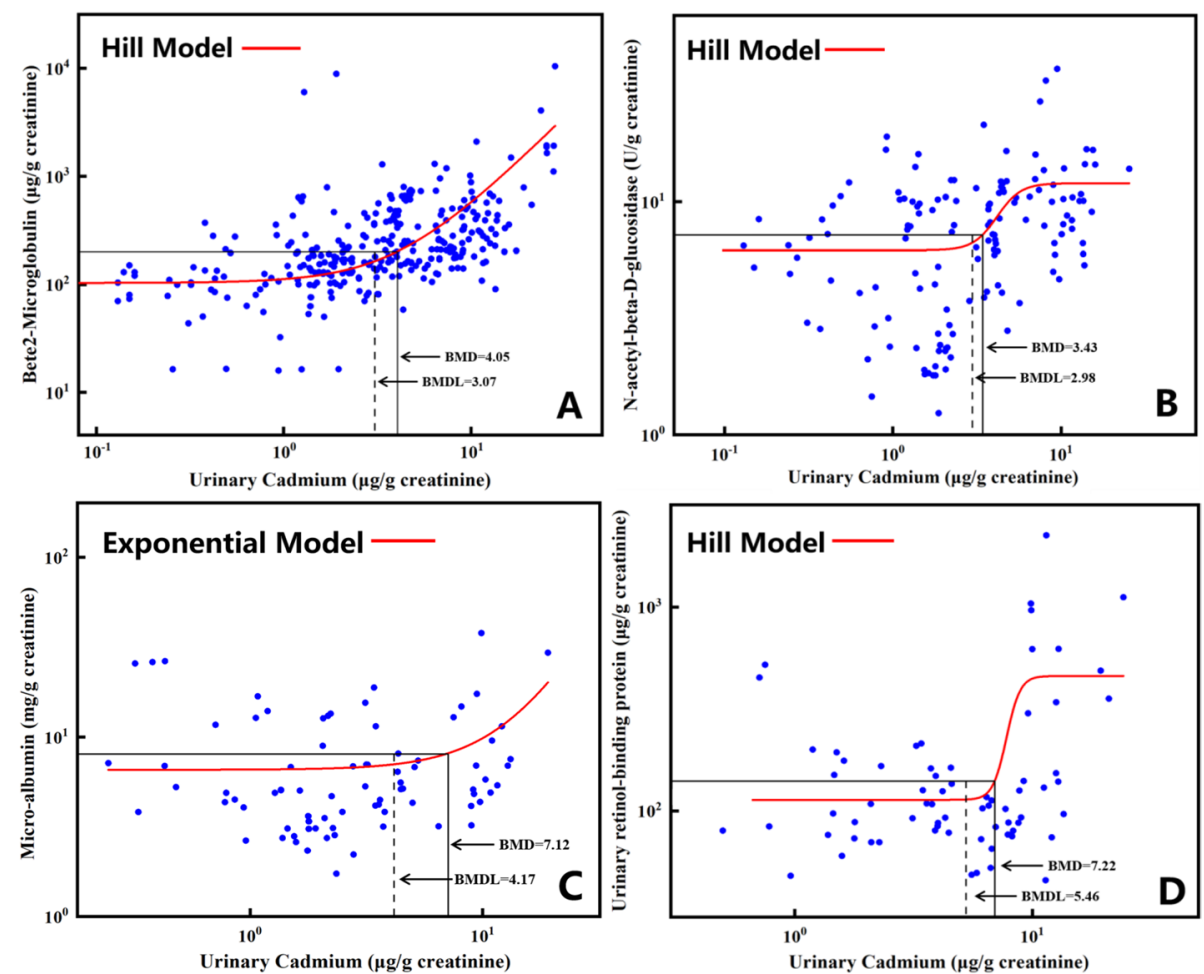

Fig. 3 Dose-response relationship between U-Cd and effect biomarkers. (The red solid curve is a fitted dose-response model (Hill or Exponential model). The horizontal line corresponds to a $5 \%$ change of the range of the response in the background $(B M R=0.05)$. The intersections of the horizontal line and the curve is the BMD. The BMDL is illustrated by the dashed-dotted line and represents the lower limit of the $95 \%$ confidence interval for BMD.)

Table 2 The $\mathrm{BMD}_{5} / \mathrm{BMDL}_{5}$ of the $\mathrm{U}-\mathrm{Cd}$ for renal injury biomarkers

\begin{tabular}{llll}
\hline Biomarkers & BMD model & BMD $_{\mathbf{5}}(\boldsymbol{\mu g} \mathbf{g} \mathbf{g} \mathbf{C r})$ & $\begin{array}{l}\mathbf{B M D L}_{\mathbf{5}} \\
(\boldsymbol{\mu g} / \mathbf{g} \mathbf{C r})\end{array}$ \\
\hline$\beta_{2}-M G$ & Hill & 4.05 & 3.07 \\
NAG & Hill & 3.43 & 2.98 \\
mALB & Exponential & 7.12 & 4.17 \\
RBP & Hill & 7.22 & 5.46 \\
\hline
\end{tabular}

$1 \%-10 \%)$ above the background level [21]. Because BMD can make full use of dose-response data and has lower dependence on experimental dose, which increases the reliability and accuracy of the results, it has been widely used in risk assessment [22].

$\mathrm{U}-\mathrm{Cd}$ is the main indicator reflecting the degree of $\mathrm{Cd}$ accumulation in the body under long-term exposure, while blood $\mathrm{Cd}$ represents the $\mathrm{Cd}$ that enters the body more recently [23]. Choosing U-Cd as the internal exposure marker can well reflect the effect of long-term Cd exposure on the renal injury biomarkers. Renal injury is the main toxic effect caused by chronic low-dose $\mathrm{Cd}$ exposure [24]. $\beta_{2}$-MG, RBP and NAG are biomarkers of

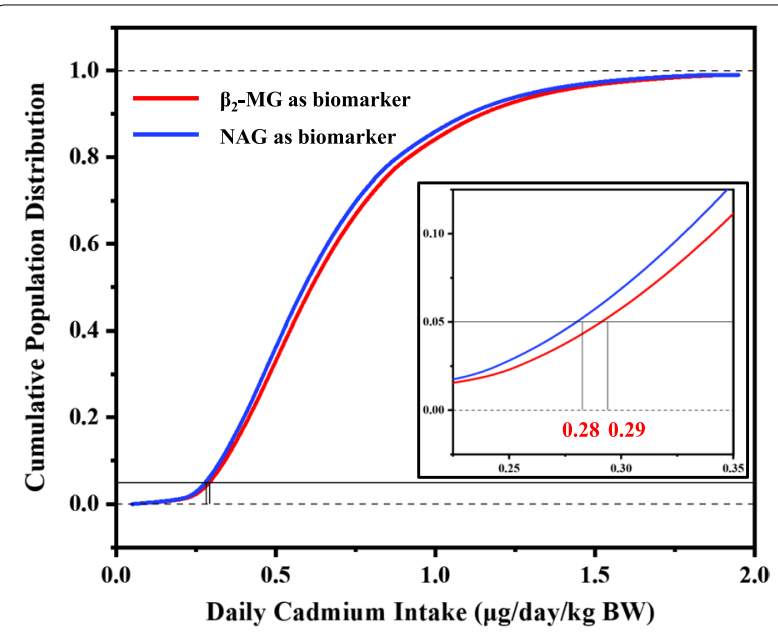

Fig. 4 Cumulative population frequency distribution of daily dietary Cd expose considering NAG and $\beta 2-M G$ as biomarkers to calculate $\mathrm{U}-\mathrm{Cd}$ threshold

renal tubular injury, and mALB is a biomarker of renal glomerular insufficiency [25]. This study showed that $\beta_{2}$-MG and NAG were more sensitive to the changes in $\mathrm{U}-\mathrm{Cd}$. This suggested that tubular biomarkers were 
more sensitive to environmental $\mathrm{Cd}$ exposure than glomerular biomarkers, which was consistent with previous research [25]. However, the correlation between $\mathrm{U}-\mathrm{Cd}$ and biomarkers of kidney function will be affected by many aspects such as normal variation in renal function (including changes in urinary flow) and concentration adjustment methods (creatinine, specific gravity, etc.). Low-level urinary $\mathrm{Cd}$ corrected with creatinine may cause a false association between $\mathrm{Cd}$ exposure and protein excretion [26]. Moreover, it is still inconclusive whether $\beta_{2}$-MG or NAG can better reflect the degree of kidney injury. An 8-year follow-up study conducted in China's Cd-contaminated area showed that monitoring $\beta_{2}$-MG can provide more comprehensive information on renal tubular function changes than NAG [27]. However, Moriguchi $J$ et al. found that the correlation coefficient between U-Cd and NAG was higher than $\beta_{2}-\mathrm{MG}$, and NAG could be used as the most sensitive biomarker for monitoring renal tubular dysfunction for residents in non-polluted areas [28].

The safety threshold of U-Cd in Chinese $(2.98 \mu \mathrm{g} / \mathrm{g}$ $\mathrm{Cr})$ obtained in this study is lower than the EFSA result $(4 \mu \mathrm{g} / \mathrm{g} \mathrm{Cr})[14]$, which was based on the U-Cd and $\beta_{2^{-}}$ MG data in populations around the world. This could be caused by the fact that the data of EFSA contained extremely high values $\left(\beta_{2}-\mathrm{MG}>100,000 \mu \mathrm{g} / \mathrm{g} \mathrm{Cr}\right)$ and affected the overall distribution of the model, resulting in higher BMDL. Other studies also supported a relative lower threshold of U-Cd. A recent evaluation by the International Union on Pure and Applied Chemistry (IUPAC) estimated a LOAEL for renal dysfunction of $2 \mathrm{nmol} / \mathrm{mmol} \mathrm{Cr}(2 \mu \mathrm{g} / \mathrm{g} \mathrm{Cr})$ [29]. A study in China explored U-Cd limits in a polluted area in southwest China and determined $\mathrm{BMDL}_{5}$ to be $3.48 \mu \mathrm{g} / \mathrm{g} \mathrm{Cr}$ [30]. The $\mathrm{BMDL}_{5}$ of U-Cd based on $\beta_{2}$-MG in non-polluted areas in Zhejiang, China, was calculated to be $0.62-$ $0.64 \mu \mathrm{g} / \mathrm{g} \mathrm{Cr}$ [31]. Another study of residents in five different regions of China calculated the $\mathrm{BMDL}_{10}$ of $\mathrm{U}-\mathrm{Cd}$ based on $\beta_{2}$-MG to be 1.69-2.00 $\mu \mathrm{g} / \mathrm{g} \mathrm{Cr}$ [32]. Different characteristics of $\mathrm{Cd}$ exposure, pollution levels, and BMD analysis methods could lead to different BMDL results. The data of this study comes from a systematic analysis of nationwide researches, which includes not only ordinary residents, but also some polluted areas and occupationally exposed people. The obtained U-Cd safety threshold could cover most areas of China and represent the average level of Chinese population.

The TDI value of $\mathrm{Cd}$ in this study $(16.8 \mu \mathrm{g} /$ day for a $60 \mathrm{~kg} \mathrm{BW}$ of adults) was lower than that of EFSA $(21.6 \mu \mathrm{g} /$ day $)$ [7] and JECFA (50 $\mu \mathrm{g} /$ day) [33]. However, some cohort studies suggested that even if the dietary $\mathrm{Cd}$ intake was below the EFSA or JECFA standards, it might still increase the risk of death from cancer, cardiovascular disease, and Alzheimer's disease [34, 35]. A Swedish cohort study showed that a $32 \%$ increased risk of osteoporosis and $31 \%$ increased risk of fracture were observed when dietary $\mathrm{Cd}$ exposure was above $13 \mu \mathrm{g} /$ day [36]. The impairment caused by long-term and low-level dietary $\mathrm{Cd}$ intake in population has now been implicated in more serious health outcomes than previously perceived [37]. This study referred to the EFSA standard establishment process and used $\mathrm{BMDL}_{5}$ and $5 \%$ population risk, which was a very conservative standard.

According to China National Nutrient and Health Survey, the mean $\mathrm{Cd}$ exposure of the general population was $15.3 \mu \mathrm{g} / \mathrm{kg}$ bw/month (approximately $30.6 \mu \mathrm{g} /$ day), which was higher than the TDI in this study. Rice (contribution rate of over $55.8 \%)$, leafy vegetables $(11.8 \%)$ and wheat flour (10.5\%) were the three most important contributors to dietary $\mathrm{Cd}$ exposure. For the high exposure subpopulation with $\mathrm{Cd}$ exposure above the $95^{\text {th }}$ percentile, rice was still the main contributor $(58.6 \%)$, followed by shellfish (13.2\%) and leafy vegetables (9.2\%) [38]. Another study in non-polluted areas of China pointed out that the median lifetime cumulative $\mathrm{Cd}$ intakes was $0.5 \mathrm{~g}$ [39], higher than the result from this study $(0.37 \mathrm{~g}$, calculated based on age 60). Due to the persistent of $\mathrm{Cd}$ in the environment and its high transfer rate from soil to plant [40], maintenance of low $\mathrm{Cd}$ in crops and leafy is pivotal. The more stringent TDI value of $\mathrm{Cd}$ put forth in this study suggested the need for a revision of dietary standards of $\mathrm{Cd}$ and public measures to minimize the food-chain contamination in China.

This study is the first to explore dietary limits for Chinese population based on a systematic analysis of four effect biomarkers of $\mathrm{Cd}$ exposure, but it is still subject to following limitations. First, the included research data were from different laboratories. The detection methods of U-Cd and effect biomarkers were inconsistent, which might cause systematic errors. Second, due to the low number of studies on other effect biomarkers $\left(\alpha_{1}\right.$ microglobulin, bone density, serum calcium, etc.), only four renal injury biomarkers were analyzed. More highquality and large-scale epidemiological studies in the future are warranted to provide reliable data for sensitive effect biomarkers and health risk assessment. Third, the TK model used to derive the TDI is established based on a Swedish female cohort. Due to the regional and ethnic differences in the absorption and metabolism characteristics of $\mathrm{Cd}$ in Chinese and European, the uncertainty of the results obtained by this model increased [41]. Last, potential kidney function damage and adjustment approach of biomarker concentrations in urine samples may affect the association between U-Cd and biomarkers of kidney function [42]. As there are few related prospective studies, it has become an inevitable obstacle to assess 
the causal relationship between pollutants and adverse outcomes in environmental epidemiological research.

\section{Conclusions}

This study comprehensively analyzed the dose-response relationship between $\mathrm{U}-\mathrm{Cd}$ and renal injury biomarkers in Chinese residents. The $\mathrm{BMDL}_{5}$ of $\mathrm{U}-\mathrm{Cd}$ using $\beta_{2}$-MG and NAG as sensitive biomarkers was taken as the critical threshold of Cd exposure. Based on the TK model, a preliminary discussion on the limit standards of dietary $\mathrm{Cd}$ exposure for residents in China was conducted. This study provides a reference for formulating Chinese dietary Cd exposure limit standards.

\section{Abbreviations}

Cd: Cadmium; Cr: Creatinine; U-Cd: Urinary Cd; $\beta_{2}-M G$ : $\beta_{2}-$ Microglobulin; NAG: $\mathrm{N}$-acetyl- $\beta$-glucosidase; mALB: Microalbumin; RBP: Retinol binding Protein; TWI: Tolerable weakly intake; TDI: Tolerable dietary intake; BMD: Benchmark dose; BMDL: Lower confidence bounds of benchmark dose; BMR: Benchmark response; TK: Toxicokinetic; NOAEL: No-observed-adverse-effect-level; LOAEL: Low-observed-adverse-effect level.

\section{Supplementary Information}

The online version contains supplementary material available at https://doi. org/10.1186/s12940-021-00760-9.

Additional file 1: Table S1. Composition of gender and occupation sample size (absolute values and percentage) for different kidney injury indicators. Table S2. Data distribution characteristics of age, gender, and occupational exposure subgroups of $\mathrm{U}-\mathrm{Cd}$ and responder in different data sets. Table S3. Study-ID and corresponding references for urinary cadmium (U-Cd) and $\beta 2$-microglobulin ( $\beta 2-M G)$. Table S4. Study-ID and corresponding references for urinary cadmium ( $U-C d)$ and $N$-acetyl- $\beta$ glucosidase (NAG).Table S5. Study-ID and corresponding references for urinary cadmium (U-Cd) and microalbumin (mALB). Table S6. Study-ID and corresponding references for urinary cadmium (U-Cd) and retinol binding Protein (RBP).

\section{Acknowledgements}

This work was supported by the National Key R\&D Program of China of Ministry of Science and Technology of the People's Republic of China (No. 2017YFC1600500, 2017YFC1600200), and the Shanghai Sailing Program (No. 21YF1418500)

\section{Authors' contributions}

All authors have contributed substantially to this work. Ying Qing: Conceptualization, Methodology, Data curation, Writing-original draft. Writing-review \& editing. Jiaqi Yang: Methodology, Software, Writing-review \& editing. Yuanshen Zhu: Data curation. Yongzhen Li: Data curation. Weiwei Zheng: Writing-review \& editing. Min Wu: Resources. Gengsheng He: Project administration, Validation, Supervision, Funding acquisition. The author(s) read and approved the final manuscript.

\section{Availability of data and materials}

The datasets used and/or analyzed during the current study are available from the corresponding author on reasonable request.

\section{Declarations}

Ethics approval and consent to participate Not applicable.
Consent for publication

Not applicable.

\section{Competing interests}

The authors declared that they have no known competing financial interests or personal relationships that could have appeared to influence the work reported in this paper.

\section{Author details}

${ }^{1}$ School of Public Health/Key Laboratory of Public Health Safety, Ministry of Education, Department of Nutrition and Food Science, Fudan University, No. 130 Dongan Road, Shanghai 200032, China. ${ }^{2}$ Department of Environmental Health, School of Public Health, Fudan University, Shanghai 200032, China.

Received: 24 February 2021 Accepted: 18 June 2021

Published online: 30 June 2021

\section{References}

1. Simmons R, Pongsakul P, Chaney RL, Saiyasitpanich D, Klinphoklap S, Nobuntou $\mathrm{W}$. The relative exclusion of zinc and iron from rice grain in relation to rice grain cadmium as compared to soybean: Implications for human health. Plant Soil. 2003:257:163-70.

2. Tchounwou PB, Yedjou CG, Patlolla AK, Sutton DJ. Heavy metal toxicity and the environment. Exp Suppl. 2012;101:133-64.

3. He ZL, Yang XE, Stoffella PJ. Trace elements in agroecosystems and impacts on the environment. J Trace Elem Med Biol. 2005;19(2-3):125-40.

4. Rafati Rahimzadeh M, Rafati Rahimzadeh M, Kazemi S, Moghadamnia AA. Cadmium toxicity and treatment: an update. Caspian J Intern Med. 2017:8(3):135-45.

5. Vacchi-Suzzi C, Eriksen KT, Levine K, McElroy J, Tjonneland A, RaaschouNielsen $\mathrm{O}$, Harrington JM, Meliker JR. Dietary intake estimates and urinary cadmium levels in Danish postmenopausal women. PLOS ONE. 2015:10(9):1-15.

6. Jarup L. Cadmium overload and toxicity. Nephrol Dial Transplant. 2002;17(Suppl 2):35-9.

7. EFSA: European Food Safety Authority (EFSA). Comparison of the approaches taken by EFSA and JECFA to establish a HBGV for Cadmium. EFSA J. 2011;9(2):1-28.

8. Dixit R, Riviere J, Krishnan K, Andersen ME. Toxicokinetics and physiologically based toxicokinetics in toxicology and risk assessment. J Toxicol Environ Health Part B. 2003;6(1):1-40.

9. EFSA: European Food Safety Authority (EFSA). Scientific opinion of PPR Panel on a request from the EFSA evaluate the suitability of exsiting methodologies and the identification of new approaches to assess cumulative and synergistic risk from pesticides to human health with a view to set MRLs for those pesticides in the frame of regulation. EFSA J. 2008;6:1-705

10. Knutsen HK, Alexander J, Barregard L, Bignami M, Bruschweiler B, Ceccatelli S, Cottrill B, Dinovi M, Edler L, Grasl-Kraupp B, et al. Risk to human health related to the presence of perfluorooctane sulfonic acid and perfluorooctanoic acid in food. EFSA J. 2018;16(12):1-284.

11. Knutsen HK, Alexander J, Barregard L, Bignami M, Bruschweiler B, Ceccatelli S, Cottrill B, Dinovi M, Edler L, Grasl-Kraupp B, et al. Risk for animal and human health related to the presence of dioxins and dioxin-like PCBs in feed and food. EFSA J. 2018;16(11):1-331.

12. Nakagawa S, Noble DW, Senior AM, Lagisz M. Meta-evaluation of metaanalysis: ten appraisal questions for biologists. BMC Biol. 2017;15(1):18.

13. Hotz P, Buchet JP, Bernard A, Lison D, Lauwerys R. Renal effects of lowlevel environmental cadmium exposure: 5-year follow-up of a subcohort from the Cadmibel study. The Lancet. 1999;354(9189):1508-13.

14. EFSA: European Food Safety Authority (EFSA). Meta-analysis of doseeffect relationship of cadmium for benchmark dose evaluation. EFSA J. 2009;254:1-62.

15. Dong Z, Hu J. Development of lead source-specific exposure standards based on aggregate exposure assessment: Bayesian inversion from biomonitoring information to multipathway exposure. Environ Sci Technol. 2012;46(2):1144-52 
16. Liu C, Li Y, Zhu C, Dong Z, Zhang K, Zhao Y, Xu Y. Benchmark dose for cadmium exposure and elevated $\mathrm{N}$-acetyl-beta-D-glucosaminidase: a meta-analysis. Environ Sci Pollut Res Int. 2016;23(20):20528-38.

17. Benchmark Dose Software (BMDS) User Guide; Using BMDS 2.6.0.1: United States Environmental Protection Agency; 2016.

18. Amzal B, Julin B, Vahter M, Wolk A, Johanson G, Åkesson A. Population toxicokinetic modeling of cadmium for health risk assessment. Environ Health Perspect. 2009;117(8):1293-301.

19. Sand S, Victorin K, Filipsson AF. The current state of knowledge on the use of the benchmark dose concept in risk assessment. J Appl Toxicol. 2008;28(4):405-21.

20. Crump K. A new method for determining allowable daily intakes*1. Fundam Appl Toxicol. 1984;4(5):854-71.

21. Crump KS, Allen B, Faustman E: The use of the benchmark dose approach in health risk assessment. . In: Risk Assessment Forum, US Environmental Protection Agency. 1995.

22. Filipsson AF, Sand S, Nilsson J, Victorin K. The benchmark dose methodreview of available models, and recommendations for application in health risk assessment. Crit Rev Toxicol. 2010;33(5):505-42.

23. Vacchi-Suzzi C, Kruse D, Harrington J, Levine K, Meliker JR. Is urinary cadmium a biomarker of long-term exposure in humans? a review. Curr Environ Health Rep. 2016;3(4):450-8.

24. Satarug S, Vesey DA, Gobe GC. Current health risk assessment practice for dietary cadmium: data from different countries. Food Chem Toxicol. 2017; 106(Pt A):430-45.

25. Jin T, Wu X, Tang Y, Nordberg M, Bernard A, Ye T, Kong Q, Lundstrom NG, Nordberg GF. Environmental epidemiological study and estimation of benchmark dose for renal dysfunction in a cadmium-polluted area in China. Biometals. 2004;17(5):525-30.

26. Akerstrom M, Sallsten G, Lundh T, Barregard L. Associations between urinary excretion of cadmium and proteins in a nonsmoking population: renal toxicity or normal physiology? Environ Health Perspect. 2013;121(2):187-91.

27. Liang Y, Lei L, Nilsson J, Li H, Nordberg M, Bernard A, Nordberg GF, Bergdahl IA, Jin T. Renal function after reduction in cadmium exposure: an 8-year follow-up of residents in cadmium-polluted areas. Environ Health Perspect. 2012;120(2):223-8.

28. Moriguchi J, Inoue Y, Kamiyama S, Horiguchi M, Murata K, Sakuragi S, Fukui Y, Ohashi F, Ikeda M. N-acetyl-beta-D-glucosaminidase (NAG) as the most sensitive marker of tubular dysfunction for monitoring residents in non-polluted areas. Toxicol Lett. 2009;190(1):1-8.

29. Nordberg GF, Bernard A, Diamond GL, Duffus JH, Illing P, Nordberg M, Bergdahl IA, Jin T, Skerfving S. Risk assessment of effects of cadmium on human health (IUPAC Technical Report). Pure Appl Chem. 2018;90(4):755-808.

30. Yan J, Huo J, Li R, Jia Z, Song Y, Chen J, Zhang L. Benchmark dose estimation of urinary and blood cadmium as biomarkers of renal dysfunction among 40-75-year-old non-smoking women in rural areas of southwest China. J Appl Toxicol. 2019;39(10):1433-43.
31. Wang $X$, Wang Y, Feng L, Tong Y, Chen Z, Ying S, Chen T, Li T, Xia H, Jiang $Z$, et al. Application of the Benchmark Dose (BMD) method to identify thresholds of cadmium-induced renal effects in non-polluted areas in China. PLOS ONE. 2016;11(8):1-12.

32. Ke S, Cheng XY, Zhang JY, Jia WJ, Li H, Luo HF, Ge PH, Liu ZM, Wang HM, $\mathrm{He} J \mathrm{~S}$, et al. Estimation of the benchmark dose of urinary cadmium as the reference level for renal dysfunction: a large sample study in five cadmium polluted areas in China. BMC Public Health. 2015;15:1-10.

33. FAO/WHO: Evaluation of certain food additives and contaminants (Seventy-third report of the Joint FAO/WHO Expert Committee on Food Additives). 2011.

34. Julin B, Wolk A, Bergkvist L, Bottai M, Akesson A. Dietary cadmium exposure and risk of postmenopausal breast cancer: a population-based prospective cohort study. Cancer Res. 2012;72(6):1459-66.

35. Julin B, Wolk A, Johansson JE, Andersson SO, Andren O, Akesson A. Dietary cadmium exposure and prostate cancer incidence: a populationbased prospective cohort study. Br J Cancer. 2012;107(5):895-900.

36. Engstrom A, Michaelsson K, Vahter M, Julin B, Wolk A, Akesson A. Associations between dietary cadmium exposure and bone mineral density and risk of osteoporosis and fractures among women. Bone. 2012;50(6):1372-8.

37. Satarug S, Vesey DA, Gobe GC. Health risk assessment of dietary cadmium intake: do current guidelines indicate how much is safe? Environ Health Perspect. 2017;125(3):284-8.

38. Song Y, Wang Y, Mao W, Sui H, Yong L, Yang D, Jiang D, Zhang L, Gong Y. Dietary cadmium exposure assessment among the Chinese population. PLOS ONE. 2017;12(5):1-12.

39. Chen X, Zhu G, Wang Z, Liang Y, Chen B, He P, Nordberg M, Nordberg GF, Ding $X$, Jin $T$. The association between dietary cadmium exposure and renal dysfunction - the benchmark dose estimation of reference levels: the ChinaCad study. J Appl Toxicol. 2018;38(10):1365-73.

40. Gan Y, Wang L, Yang G, Dai J, Wang R, Wang W. Multiple factors impact the contents of heavy metals in vegetables in high natural background area of China. Chemosphere. 2017;184:1388-95.

41. Qing Y, Yang J, Zhang Q, Zhu Y, Ruiz P, Wu M, Zhao G, Zhao Q, Liu H, Cai H, et al. Bayesian toxicokinetic modeling of cadmium exposure in Chinese population. J Hazard Mater. 2021;413:125465.

42. Weaver VM, Kotchmar DJ, Fadrowski JJ, Silbergeld EK. Challenges for environmental epidemiology research: are biomarker concentrations altered by kidney function or urine concentration adjustment? J Expo Sci Environ Epidemiol. 2016;26(1):1-8.

\section{Publisher's Note}

Springer Nature remains neutral with regard to jurisdictional claims in published maps and institutional affiliations.

\footnotetext{
Ready to submit your research? Choose BMC and benefit from:

- fast, convenient online submission

- thorough peer review by experienced researchers in your field

- rapid publication on acceptance

- support for research data, including large and complex data types

- gold Open Access which fosters wider collaboration and increased citations

- maximum visibility for your research: over $100 \mathrm{M}$ website views per year
}

At BMC, research is always in progress.

Learn more biomedcentral.com/submissions 